\title{
Mutational analysis in podocin-associated hereditary nephrotic syndrome in Polish patients: founder effect in the Kashubian population
}

\author{
Beata S. Lipska • Irena Balasz-Chmielewska • Lucyna Morzuch • Kacper Wasielewski • \\ Dominika Vetter • Halina Borzecka • Dorota Drozdz • Agnieszka Firszt-Adamczyk • \\ Ewa Gacka • Tomasz Jarmolinski • Joanna Ksiazek • Elzbieta Kuzma-Mroczkowska • \\ Mieczyslaw Litwin • Anna Medynska • Magdalena Silska • Maria Szczepanska • \\ Marcin Tkaczyk • Anna Wasilewska • Franz Schaefer • Aleksandra Zurowska • \\ Janusz Limon
}

Received: 7 March 2013 /Revised: 22 March 2013 /Accepted: 27 March 2013 /Published online: 5 May 2013

(C) The Author(s) 2013. This article is published with open access at Springerlink.com

\begin{abstract}
Hereditary nephrotic syndrome is caused by mutations in a number of different genes, the most common being NPHS2. The aim of the study was to identify the spectrum of NPHS2 mutations in Polish patients with the disease. A total of 141 children with steroid-resistant
\end{abstract}

B. S. Lipska $(\bowtie) \cdot$ L. Morzuch $\cdot$ K. Wasielewski $\cdot$ D. Vetter

J. Limon

Department of Biology and Genetics,

Medical University of Gdansk, Debinki str. 1,

80211 Gdansk, Poland

e-mail: b.lipska@gumed.edu.pl

I. Balasz-Chmielewska $\cdot$ A. Zurowska

Department of Nephrology and Hypertension for Children and

Adolescents,

Medical University of Gdansk, Debinki str. 7,

80211 Gdansk, Poland

\section{H. Borzecka}

Department of Pediatric Nephrology,

Medical University of Lublin, Chodzki str. 2,

20093 Lublin, Poland

D. Drozdz

Pediatric Nephrology and Dialysis Unit, Jagiellonian University Medical College, Cracow, Wielicka str. 265,

30663 Cracow, Poland

\author{
A. Firszt-Adamczyk \\ Department of Pediatrics and Nephrology, \\ The Ludwik Rydygier Hospital in Torun - Children Hospital, \\ Konstytucji 3 Maja str. 42, \\ 87100 Torun, Poland \\ E. Gacka \\ Child Nephrology Department, Center of Pediatrics and Oncology \\ in Chorzow, Truchana str. 7 , \\ 41500 Chorzow, Poland
}

nephrotic syndrome (SRNS) were enrolled in the study. Mutational analysis included the entire coding sequence and intron boundaries of the NPHS2 gene. Restriction fragment length polymorphism (RFLP) and TaqMan genotyping assay were applied to detect selected NPHS2 sequence

T. Jarmolinski

Miedzyrzecz Regional Hospital, Konstytucji 3 Maja str. 35, 66300 Miedzyrzecz, Poland

J. Ksiazek $\cdot$ M. Litwin

Department of Nephrology and Arterial Hypertension,

The Children's Memorial Health Institute, Dzieci Polskich Av. 20, 04730 Warsaw, Poland

\section{E. Kuzma-Mroczkowska}

Department of Pediatrics and Nephrology,

Medical University of Warsaw, Marszalkowska 24,

00576 Warsaw, Poland

\section{A. Medynska}

Department of Pediatric Nephrology, Wroclaw Medical

University, Wroclaw, Curie-Sklodowskiej str. 50/52,

50369 Wroclaw, Poland

M. Silska

Department of Pediatric Nephrology,

Poznan University of Medical Sciences, Szpitalna str. 27/33,

Poznan 60572, Poland

\section{Szczepanska}

Department and Clinic of Children's Nephrology,

Medical University of Silesia, 3 Maja str. 13/15,

41800 Zabrze, Poland 
variants in 575 population-matched controls. Twenty patients $(14 \%)$ had homozygous or compound heterozygous NPHS2 mutations, the most frequent being c.1032delT found in 11 children and p.R138Q found in four patients. Carriers of the c.1032delT allele were exclusively found in the Pomeranian (Kashubian) region, suggesting a founder effect origin. The $14 \%$ NPHS2 gene mutation detection rate is similar to that observed in other populations. The heterogeneity of mutations detected in the studied group confirms the requirement of genetic testing the entire NPHS2 coding sequence in Polish patients, with the exception of Kashubs, who should be initially screened for the c.1032delT deletion.

Keywords NPHS2 - Steroid-resistant nephrotic syndrome · Founder effect $\cdot$ Kashubian population

\section{Introduction}

Steroid-resistant nephrotic syndrome (SRNS) occurs at an estimated incidence of 1 per 200,000 children. Genetic causes can be identified in nearly $50 \%$ of affected children with this highly heterogeneous disorder (Löwik et al. 2009; Benoit et al. 2010). Genetic forms of SRNS do not respond to intensified immunosuppressive treatment and progress inevitably to end-stage kidney disease, but, on the other hand, have minimal risk of post-transplant recurrence. Hence, genetic testing is of eminent clinical relevance in this complex group of patients (Jungraithmayr et al. 2011; Santín et al. 2011a).

In hereditary SRNS, abnormalities in podocyte-specific genes cause structural defects of the glomerular filtration barrier (Hinkes et al. 2007; Löwik et al. 2009). Defective genes involve the structure and function of the slit diaphragm (e.g. NPHS1, NPHS2), the actin cytoskeleton (e.g. $A C T N 4, I N F 2$ ) or podocyte differentiation (WT1) (Löwik et al. 2009; Benoit et al. 2010; Santín et al. 2011a).

NPHS2 encodes podocin, a membrane protein that links the slit diaphragm protein nephrin to the cytoskeleton.

\section{Tkaczyk}

Nephrology Division, Polish Mother's Memorial Hospital Research Institute, Rzgowska str. 281/289,

93338 Lodz, Poland

\section{A. Wasilewska}

Department of Pediatrics and Nephrology,

Medical University of Bialystok, Waszyngtona str. 17,

15274 Bialystok, Poland

\section{F. Schaefer}

Division of Pediatric Nephrology,

Center for Pediatric and Adolescent Medicine,

University of Heidelberg, Im Neuenheimer Feld 430,

69120 Heidelberg, Germany
NPHS2 mutations constitute the most common genetic cause of SRNS (Hinkes et al. 2007; Santín et al. 2011b; Lipska et al. 2013). The NPHS2 gene is located on chromosome 1p25-31 and consists of eight exons. To date, approximately 120 different point mutations localised along the entire coding sequence of the gene have been reported.

The aim of the study was to determine the prevalence and spectrum of NPHS2 gene mutations in a nation-wide cohort of Polish children with SRNS and to compare the spectrum of mutations with those described in other European populations.

\section{Materials and methods}

Mutational screening

A total of 141 patients with a clinical diagnosis of SRNS from 13 Polish paediatric nephrology centres were enrolled in the study. Detailed analysis of the clinical parameters of the studied group is out of the scope of the current report and will be the subject of a separate study.

DNA was extracted from blood samples using the standard phenol-chloroform procedure. The complete coding sequence of the NPHS2 gene, including splice junctions, was subject to direct bi-directional sequencing (Applied Biosystems). All novel variants were verified in the dbSNP, the 1000 Genomes catalogue and the NHLBI Exome Sequencing Project. The trans-character of the compound heterozygous cases was confirmed by testing parents. To assess the effect of the detected novel sequence variants on the structure and function of the protein, a number of bioinformatics tools were used, including the UCSC Genome Bioinformatics and UniProtKB web resources, along with the PolyPhen-2 and SIFT online algorithms. The Human Splicing Finder and ESEfinder web interfaces were used to evaluate the potential effect on the splicing process.

Population genotyping

Dried blood specimens from 575 consecutively screened neonates representative for the Kashubian districts of North Poland were used as a population-matched control group. DNA was extracted from $1-3-\mathrm{mm}^{2}$ pieces of dried blood specimens that were incubated in $50 \mu \mathrm{l}$ of TE buffer at $95{ }^{\circ} \mathrm{C}$ for $1 \mathrm{~h}$; after incubation, samples were centrifuged at room temperature at $1,400 \times \mathrm{g}$ for $10 \mathrm{~min}$ to eliminate physical contamination. The supernatant was used as the DNA template. The NPHS2 p.R229Q genotype was determined by restriction fragment length polymorphism (RFLP) using Bsu15I (ClaI) enzyme (Thermo Scientific), while the c.1032delT genotype was analysed by real-time polymerase chain reaction (real-time PCR) assay with allele-specific TaqMan probes (LightCycler 480 II, Roche). 
Written informed consent was obtained from the relevant guardians of the children and from patients themselves, whenever eligible. The study was approved by the Ethical Committee of the Medical University of Gdansk, Poland.

\section{Results}

Spectrum of NPHS2 mutations in Polish patients

Twenty patients comprising $14 \%$ of the studied cohort fulfilled the criteria of podocin-associated SRNS. Fifteen were compound heterozygous cases; 11 of these harboured the c.1032delT mutation and four carried other known mutations. The remaining five cases showed homozygous mutations (Table 1).

Ten sequence variants, including three novel ones, were identified in 34 (24\%) SRNS patients. Variants were located along the entire coding sequence of the gene. The most frequent NPHS2 variant was the non-neutral polymorphism c.686G $>$ A (rs61747728, commonly referred to as p.R229Q), which was detected in 24 patients $(21 \%)$. In 14 of these, c. $686 \mathrm{G}>\mathrm{A}$ contributed to disease-causing compound heterozygosity, whereas two patients were homozygous and eight patients were heterozygous for c. $686 \mathrm{G}>\mathrm{A}$ without any further variants in NPHS2. All carriers of the c.1032delT mutation came from a confined geographical area, the Kashubian region in North Poland (Fig. 1).

Three novel NPHS2 sequence variants were found. These included two exonic single nucleotide alterations, c.322A $>\mathrm{G}$ and c.732 $>\mathrm{C}$, present in heterozygous state in individual patients and an intronic c. $872+1 \mathrm{G}>\mathrm{A}$ substitution present in homozygous state in a child from a consanguineous marriage. None of the novel variants is catalogued in the three large human variation databases: dbSNP, 1000 Genomes and NHLBI Exome Variant Server. At the protein level, c.322A $>$ G results in the substitution of a non-conservative residue (p.I108V) by a similar hydrophobic branched amino acid within the hydrophobic intra-membrane domain, while c.732T $>\mathrm{C}$ is a silent (synonymous) mutation. Accordingly, the SIFT and PolyPhen in silico algorithms advocate for their benign character. Nonetheless, the two exonic variants lie near splice-sites at the exon/intron boundaries and could affect mRNA processing. Likewise, the third novel variant affects the first nucleotide of the intron 8 and has been identified by in silico tools as a mandatory splice-site mutation.

Age of onset and the mutation detection rate

Mutations in the NPHS2 gene were most frequent in patients diagnosed within the first year of life $(26 \%, 9 / 35)$, and in patients with congenital nephrotic syndrome in particular
(33\%; 8/24). Toddlers and school children had the lowest rate of $8 \%(7 / 84)$. Adolescents diagnosed with the disease aged over 10 years had an $18 \%$ mutation detection rate $(4 / 22)$. All teenagers were compound heterozygous cases for the c. $686 \mathrm{G}>\mathrm{A}$ polymorphism and an NPHS2 mutation.

Evaluation of the founder effect for NPHS2 mutations in the Kashubian population

A total of 575 consecutive neonatal dry blood spots representative for five Kashubian districts of North Poland were evaluated for the p.R229Q polymorphism and the c.1032delT mutation in NPHS2. The genotype frequencies of the p.R229Q polymorphism were consistent with the Hardy-Weinberg equilibrium. The p.R229Q minor allele frequency (MAF) was $6.5 \%$ for the entire group (Fig. 1). In the entire cohort, only one subject from the Koscierzyna district was found to carry a heterozygous c.1032delT mutation (frequency of the mutated allele $<1 / 1,000$ ), without any other variants in the NPHS2 gene.

\section{Discussion}

Currently, genetic screening in paediatric SRNS is based on initial testing of the entire coding sequence of NPHS2, with subsequent extended screening of other genes in line with the identified phenotype (age at onset, kidney biopsy findings, presence of extra-renal symptoms) (Santín et al. 2011a).

NPHS2 gene mutations are estimated to account for 10 $30 \%$ of SRNS cases, depending on ethnicity, size of the analysed group, accuracy of the clinical diagnosis and the mean age at diagnosis (Santín et al. 2011b). The screening of the entire coding region of the NPHS2 gene led to a conclusive diagnosis in $14 \%$ of our unselected consecutive Polish SRNS cohort, a figure similar to the rates reported for other European populations (French: Weber et al. 2004; German: Ruf et al. 2004; Italian: Caridi et al. 2009; Spanish: Santín et al. 2011b; Hungarian: Kerti et al. 2013). Analysis of the mutation detection rate with respect to age at onset revealed the presence of two subgroups with relatively higher incidence of $N P H S 2$-associated disease: infants and adolescents. Since mutations in the NPHS2 gene lead to congenital structural defect of the podocytes, their association with the early onset of SRNS is already well acknowledged (Hinkes et al. 2007). Then again, compound heterozygosity status for p.R229Q has been shown to be associated with later onset and more latent course of the disease (Machuca et al. 2009; Lipska et al. 2013). In our group, all teenagers diagnosed with podocin-associated SRNS were, indeed, found to be compound heterozygous for non-neutral p.R229Q, together with an NPHS2 mutation.

The criteria for diagnosing podocin-associated SRNS include a homozygous NPHS2 mutation, compound 


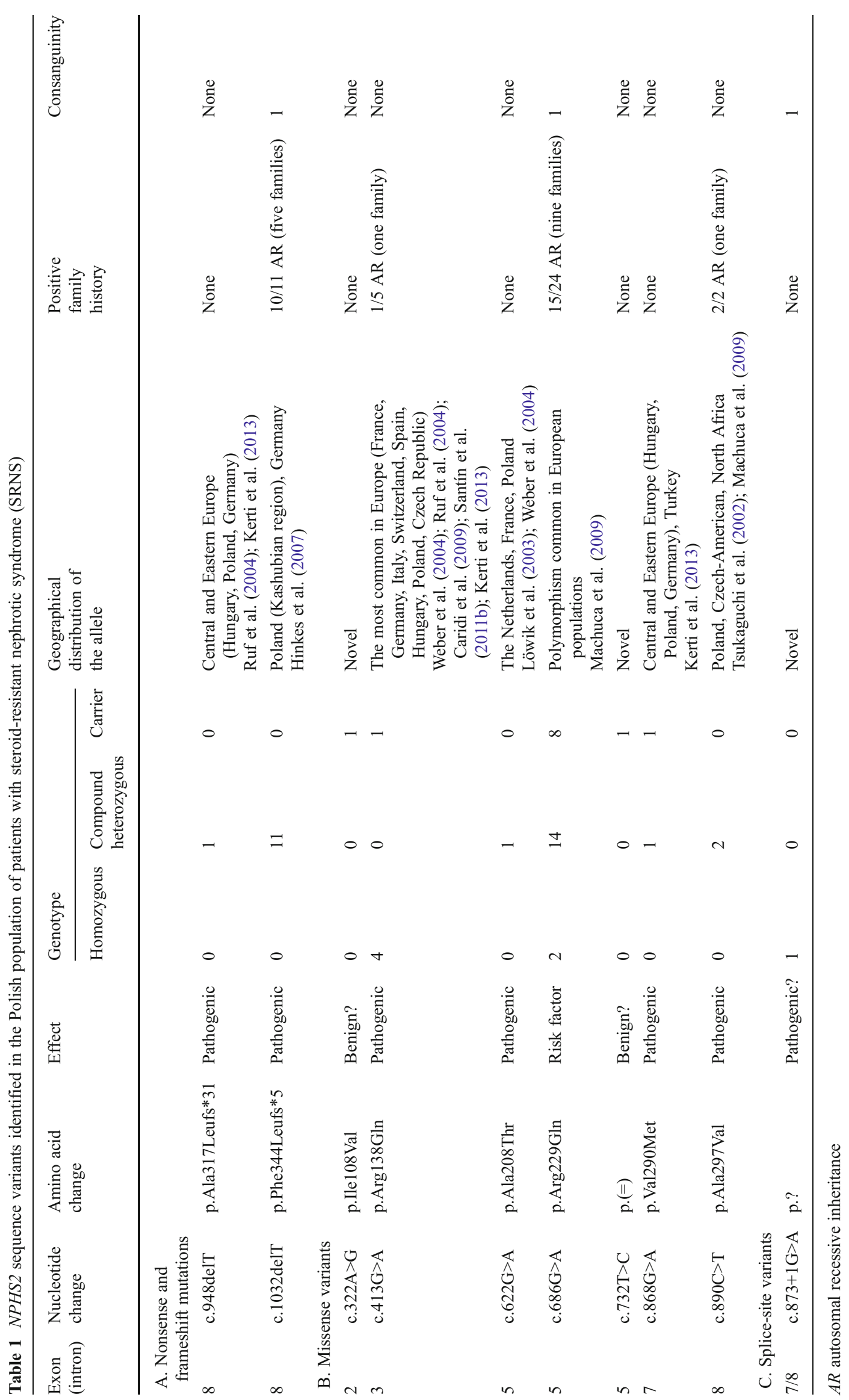


Fig. 1 Geographical distribution of NPHS2 sequence variants in the Polish population of steroid-resistant nephrotic syndrome (SRNS) patients. Left distribution of the NPHS2 mutations in Poland. Right distribution of the NPHS2 mutations in the Kashubian region of North Poland. Gray shading districts with the highest percentage of Kashubian inhabitants. The named dots represent major towns. Minor allele frequency (MAF) values for the nonneutral p.R229Q polymorphism are presented as \%

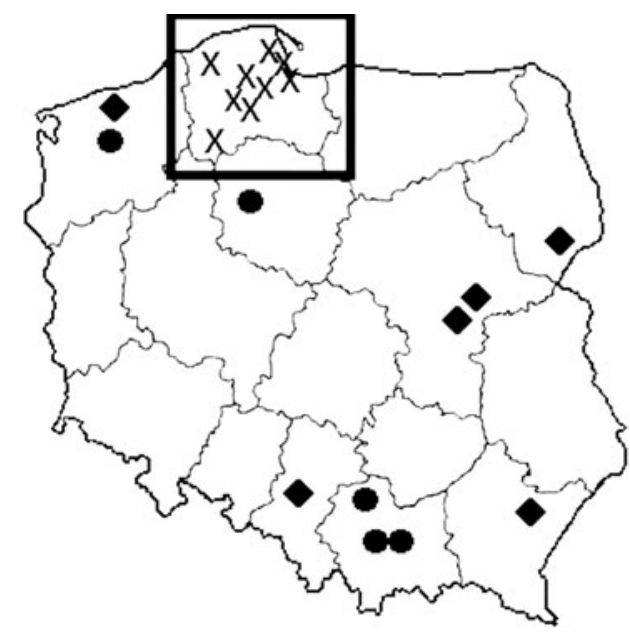

heterozygous NPHS2 mutations or a heterozygous NPHS2 mutation trans-associated with the non-neutral p.R229Q polymorphism (Machuca et al. 2009). In line with these guidelines, in the subjects homozygous for the p.R229Q polymorphism, SRNS was not considered to be caused by this common podocin variant. Also, a single heterozygous NPHS2 mutation was not sufficient for diagnosis, as it has been shown that the presence of a single NPHS2 variant does not modify the risk of developing the disease (Caridi et al. 2009).

We noted a geographical cluster of patients carrying the c.1032delT mutation in North Poland, for the most part in the Kashubian districts, suggestive of a founder effect (Fig. 1). Kashubs are an ethnic group of West Slavs who have populated Northern Poland since the Migration Period (5th to 7 th century A.D.). Despite substantial coinhabitation of the region by both Poles and Germans over the following centuries, this ethnic group has preserved their cultural identity (Obracht-Prondzynski and Wicherkiewicz 2011). Such a divergence has also been observed on the genetic level. Confirmation of the genetic distinctiveness of the Kashubian from other Polish regional populations comes from studies of serum protein markers and Y-chromosomal SNPs and short tandem repeats (STRs), which have also shown hardly detectable German paternal ancestry admixture (Walter et al. 1992; Rębała et al. 2012). Further evidence comes from the recent mutational studies of a few Mendelian traits, where particular mutations have been almost exclusively detected in patients from this region. These include familiar hypercholesterolaemia (c.662A $>\mathrm{G}$ mutation in the $L D L R$ gene; Chmara et al. 2010), familial breast cancer (c.3700_3704del in the BRCA1 gene; Brozek et al. 2011) and long-chain 3-hydroxyacyl-CoA dehydrogenase deficiency (c.1528G $>$ A mutation in the HADHA gene; Piekutowska-Abramczuk et al. 2010). The latter study has demonstrated a seven times higher incidence rate of this disorder and proven a founder effect among Kashubian patients, which led to the introduction of a neonatal screening programme in the region.

Post-war resettlements resulted in homogenisation of the contemporary Polish paternal lineages (Rębała et al. 2012). At present, the population of ca. 550,000 Kashubs is concentrated in five rural districts of the Pomeranian Region (Fig. 1), accounting for approximately $25 \%$ of its contemporary residents. All but one of the c.1032delT mutation carriers live in this region. This mutation has not been catalogued in human variation databases to date, and the only patient in whom this mutation was hitherto described lives in Northern Germany (Hildebrandt, personal communication). However due to World War II-mediated massive human resettlements, one cannot exclude Kashubian origin of this patient.

To test our hypothesis of a Kashubian founder effect, we performed a population screening study in almost 600 consecutive neonates from North Poland. Only a single subject was found to be heterozygous for c.1032delT. The frequency of the non-neutral p.R229Q polymorphism, which was trans-associated with the mutation in all the Kashubian SRNS patients, was found to be two times higher than the average $3.5 \%$ observed in most European populations (Machuca et al. 2009). The regional particularities can be readily applied in the diagnostic setting. A costeffective approach to genetic testing in patients from the Kashubian region would be to pre-screen exons 5 and 8 of NPHS2 (loci of p.R229Q and c.1032delT, respectively).

Conversely, NPHS2 mutational analysis in patients living in other provinces of Poland has to incorporate the entire coding sequence of the gene. Similarly to studies performed on other European populations, in the analysed group of patients, a few rare mutations located in diverse exons have been diagnosed (Weber et al. 2004; Ruf et al. 2004; Caridi et al. 2009; Santín et al. 2011b; Kerti et al. 2013). The most common mutation in Caucasian populations, namely, p.R138Q, was also the most common in Polish patients (with 
the exception of Kashubs). This was followed by two mutations typical for Central and Eastern European populations, namely, c.948delT and p.V290M. These variants have previously been reported not only in Slavic nations, but also in German and Hungarian patients (Ruf et al. 2004; Kerti et al. 2013), echoing the complex history of the region.

\section{Conclusions}

In an unselected national cohort of Polish steroid-resistant nephrotic syndrome (SRNS) patients, the most commonly detected mutation was c.1032delT, which was exclusively detected in patients from Kashubian districts of North Poland, suggestive of a founder effect. Most patients carried compound heterozygous mutations, together with the nonneutral p.R229Q polymorphism. We recommend first-line analysis of exons 5 and 8 (the respective loci of p.R229Q and c.1032delT) in patients from this region.

Acknowledgements This work has been financed by the Polish Ministry of Science and Higher Education grant N402 631840 and also received support from the E-Rare project PodoNet and from the EU FP7-funded project EURenOmics (grant no. 2012-305608). We are grateful to Dr. K. Rębała from the Department of Forensic Medicine, Medical University of Gdansk, Poland, for the discussion and critical reading of the manuscript.

Open Access This article is distributed under the terms of the Creative Commons Attribution License which permits any use, distribution, and reproduction in any medium, provided the original author(s) and the source are credited.

\section{References}

Benoit G, Machuca E, Antignac C (2010) Hereditary nephrotic syndrome: a systematic approach for genetic testing and a review of associated podocyte gene mutations. Pediatr Nephrol 25:16211632

Brozek I, Cybulska C, Ratajska M, Piatkowska M, Kluska A, Balabas A, Dabrowska M, Nowakowska D, Niwinska A, Pamula-Pilat J, Tecza K, Pekala W, Rembowska J, Nowicka K, Mosor M, Januszkiewicz-Lewandowska D, Rachtan J, Grzybowska E, Nowak J, Steffen J, Limon J (2011) Prevalence of the most frequent $B R C A 1$ mutations in Polish population. J Appl Genet $52: 325-330$

Caridi G, Gigante M, Ravani P, Trivelli A, Barbano G, Scolari F, Dagnino M, Murer L, Murtas C, Edefonti A, Allegri L, Amore A, Coppo R, Emma F, De Palo T, Penza R, Gesualdo L, Ghiggeri GM (2009) Clinical features and long-term outcome of nephrotic syndrome associated with heterozygous NPHS1 and NPHS2 mutations. Clin J Am Soc Nephrol 4:1065-1072

Chmara M, Wasag B, Zuk M, Kubalska J, Wegrzyn A, BednarskaMakaruk M, Pronicka E, Wehr H, Defesche JC, Rynkiewicz A, Limon J (2010) Molecular characterization of Polish patients with familial hypercholesterolemia: novel and recurrent $L D L R$ mutations. J Appl Genet 51:95-106

Hinkes BG, Mucha B, Vlangos CN, Gbadegesin R, Liu J, Hasselbacher K, Hangan D, Ozaltin F, Zenker M, Hildebrandt F; Arbeitsgemeinschaft für Paediatrische Nephrologie Study Group (2007) Nephrotic syndrome in the first year of life: two thirds of cases are caused by mutations in 4 genes (NPHS1, NPHS2, WT1, and LAMB2). Pediatrics 119:e907-e919

Jungraithmayr TC, Hofer K, Cochat P, Chernin G, Cortina G, Fargue S, Grimm P, Knueppel T, Kowarsch A, Neuhaus T, Pagel P, Pfeiffer KP, Schäfer F, Schönermarck U, Seeman T, Toenshoff B, Weber S, Winn MP, Zschocke J, Zimmerhackl LB (2011) Screening for NPHS2 mutations may help predict FSGS recurrence after transplantation. J Am Soc Nephrol 22:579-585

Kerti A, Csohány R, Szabó A, Arkossy O, Sallay P, Moriniére V, VegaWarner V, Nyírő G, Lakatos O, Szabó T, Lipska BS, Schaefer F, Antignac C, Reusz G, Tulassay T, Tory K (2013) NPHS2 p.V290M mutation in late-onset steroid-resistant nephrotic syndrome. Pediatr Nephrol 28:751-757

Lipska BS, Iatropoulos P, Maranta R, Caridi G, Ozaltin F, Anarat A, Balat A, Gellermann J, Trautmann A, Erdogan O, Saeed B, Emre S, Bogdanovic R, Azocar M, Balasz-Chmielewska I, Benetti E, Caliskan S, Mir S, Melk A, Ertan P, Baskin E, Jardim H, Davitaia T, Wasilewska A, Drozdz D, Szczepanska M, Jankauskiene A, Higuita LM, Ardissino G, Ozkaya O, Kuzma-Mroczkowska E, Soylemezoglu O, Ranchin B, Medynska A, Tkaczyk M, Peco-Antic A, Akil I, Jarmolinski T, Firszt-Adamczyk A, Dusek J, Simonetti GD, Gok F, Gheissari A, Emma F, Krmar RT, Fischbach M, Printza N, Simkova E, Mele C, Marco Ghiggeri G, Schaefer F (2013) Genetic screening in adolescents with steroid-resistant nephrotic syndrome. Kidney Int. doi:10.1038/ki.2013.93

Löwik MM, Levtchenko EN, Monnens LA, van den Heuvel LP (2003) WT-1 and NPHS2 mutation analysis in patients with non-familial steroid-resistant focal-segmental glomerulosclerosis. Clin Nephrol 59:143-146

Löwik MM, Groenen PJ, Levtchenko EN, Monnens LA, van den Heuvel LP (2009) Molecular genetic analysis of podocyte genes in focal segmental glomerulosclerosis - a review. Eur J Pediatr 168:1291-1304

Machuca E, Benoit G, Antignac C (2009) Genetics of nephrotic syndrome: connecting molecular genetics to podocyte physiology. Hum Mol Genet 18:R185-R194

Obracht-Prondzynski C, Wicherkiewicz T (2011) The Kashubs: past and present. Peter Lang AG, Bern

Piekutowska-Abramczuk D, Olsen RK, Wierzba J, Popowska E, Jurkiewicz D, Ciara E, Ołtarzewski M, Gradowska W, SykutCegielska J, Krajewska-Walasek M, Andresen BS, Gregersen N, Pronicka E (2010) A comprehensive HADHA c.1528G $>\mathrm{C}$ frequency study reveals high prevalence of long-chain 3hydroxyacyl-CoA dehydrogenase deficiency in Poland. J Inherit Metab Dis. doi:10.1007/s10545-010-9190-7

Rębała K, Martínez-Cruz B, Tönjes A, Kovacs P, Stumvoll M, Lindner I, Büttner A, Wichmann HE, Siváková D, Soták M, QuintanaMurci L, Szczerkowska Z, Comas D; Genographic Consortium (2012) Contemporary paternal genetic landscape of Polish and German populations: from early medieval Slavic expansion to post-World War II resettlements. Eur J Hum Genet 21:415-422. doi:10.1038/ejhg.2012.190

Ruf RG, Lichtenberger A, Karle SM, Haas JP, Anacleto FE, Schultheiss M, Zalewski I, Imm A, Ruf EM, Mucha B, Bagga A, Neuhaus T, Fuchshuber A, Bakkaloglu A, Hildebrandt F; Arbeitsgemeinschaft Für Pädiatrische Nephrologie Study Group (2004) Patients with mutations in NPHS2 (podocin) do not respond to standard steroid treatment of nephrotic syndrome. J Am Soc Nephrol 15:722-732 
Santín S, Bullich G, Tazón-Vega B, García-Maset R, Gimenéz I, Silva I, Ruíz P, Ballarín J, Torra R, Ars E (2011a) Clinical utility of genetic testing in children and adults with steroid-resistant nephrotic syndrome. Clin J Am Soc Nephrol 6:1139-1148

Santín S, Tazón-Vega B, Silva I, Cobo MÁ, Giménez I, Ruíz P, García-Maset R, Ballarín J, Torra R, Ars E; FSGS Spanish Study Group (2011b) Clinical value of NPHS2 analysis in early- and adult-onset steroidresistant nephrotic syndrome. Clin J Am Soc Nephrol 6:344-354

Tsukaguchi H, Sudhakar A, Le TC, Nguyen T, Yao J, Schwimmer JA, Schachter AD, Poch E, Abreu PF, Appel GB, Pereira AB, Kalluri
R, Pollak MR (2002) NPHS2 mutations in late-onset focal segmental glomerulosclerosis: R229Q is a common diseaseassociated allele. J Clin Invest 110:1659-1666

Walter H, Danker-Hopfe H, Lemmermann M, Lorenz M (1992) Investigations on the variability of four genetic serum protein markers in Poland. Z Morph Anthrop 79:203-214

Weber S, Gribouval O, Esquivel EL, Morinière V, Tête MJ, Legendre C, Niaudet P, Antignac C (2004) NPHS2 mutation analysis shows genetic heterogeneity of steroid-resistant nephrotic syndrome and low post-transplant recurrence. Kidney Int 66:571-579 